\title{
Impact of Cardiovascular Risk Factors on Medical Expenditure: Evidence From Epidemiological Studies Analysing Data on Health Checkups and Medical Insurance
}

\author{
Koshi Nakamura \\ Department of Epidemiology and Public Health, Kanazawa Medical University, Uchinada, Ishikawa, Japan
}

Received May 20, 2014; accepted June 4, 2014; released online July 26, 2014

Copyright $(\subseteq 2014$ Koshi Nakamura. This is an open access article distributed under the terms of Creative Commons Attribution License, which permits unrestricted use, distribution, and reproduction in any medium, provided the original author and source are credited.

\begin{abstract}
Concerns have increasingly been raised about the medical economic burden in Japan, of which approximately $20 \%$ is attributable to cardiovascular disease, including coronary heart disease and stroke. Because the management of risk factors is essential for the prevention of cardiovascular disease, it is important to understand the relationship between cardiovascular risk factors and medical expenditure in the Japanese population. However, only a few Japanese epidemiological studies analysing data on health checkups and medical insurance have provided evidence on this topic. Patients with cardiovascular risk factors, including obesity, hypertension, and diabetes, may incur medical expenditures through treatment of the risk factors themselves and through procedures for associated diseases that usually require hospitalization and sometimes result in death. Untreated risk factors may cause medical expenditure surges, mainly due to long-term hospitalization, more often than risk factors preventively treated by medication. On an individual patient level, medical expenditures increase with the number of concomitant cardiovascular risk factors. For single risk factors, personal medical expenditure may increase with the severity of that factor. However, on a population level, the medical economic burden attributable to cardiovascular risk factors results largely from a single, particularly prevalent risk factor, especially from mildly-to-moderately abnormal levels of the factor. Therefore, cardiovascular risk factors require management on the basis of both a cost-effective strategy of treating high-risk patients and a population strategy for reducing both the ill health and medical economic burdens that result from cardiovascular disease.
\end{abstract}

Key words: cardiovascular risk factor; medical expenditure; cohort study

\section{INTRODUCTION}

In Japan, the majority of outpatient medical services and hospitalizations are provided at approved clinics and hospitals within the medical insurance system, which regulates medical costs nationwide and is compulsory for all Japanese residents. ${ }^{1-3}$ Thus, people spend public resources to receive medical services, even though they pay up to $30 \%$ of medical expenditures for medical services they receive, in addition to monthly insurance fees. As this medical economic burden is increasing drastically each year, ${ }^{1}$ concerns regarding this issue have been raised.

Cardiovascular disease, including coronary heart disease and stroke, accounts for $20.8 \%$ of the total medical expenditure in the Japanese population and is the leading cause of medical economic burden. ${ }^{1}$ Because the management of risk factors is essential for the prevention of cardiovascular disease, it is important to understand the relationship between cardiovascular risk factors and medical expenditure in the Japanese population. However, only a few Japanese epidemiological studies analysing data on health checkups and medical insurance have provided evidence on this topic.

\section{AN INDIVIDUAL PERSPECTIVE ON THE RELATIONSHIP BETWEEN CARDIOVASCULAR RISK FACTORS AND MEDICAL EXPENDITURE}

The Shiga National Health Insurance (NHI) cohort study was one of the earliest Japanese studies on this topic. ${ }^{4-12}$ It was conducted in 7 towns and 1 village in Shiga prefecture in the central part of Japan and included 4535 community dwellers 


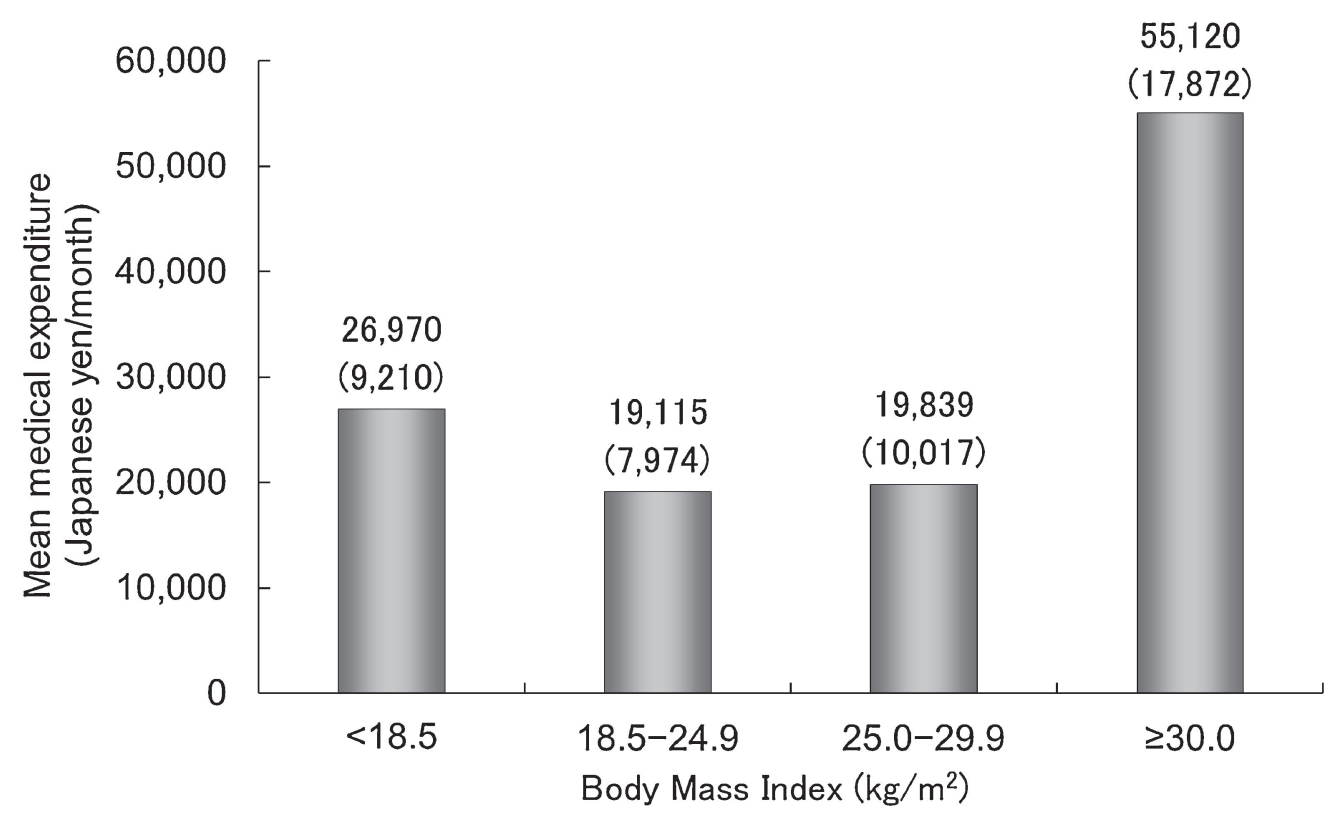

Figure 1. The crude arithmetic mean medical expenditure per month over 10 years of follow-up in Japanese medical insurance beneficiaries 40-69 years of age, grouped according to their body mass index. Numbers in parentheses represent the geometric means after adjustment for age, sex, and smoking and drinking habits (analysis of covariance, $P<0.01) .{ }^{9}$ Note: data edited for currency translation.

between the ages of 40 and 69 years who were beneficiaries of NHI, an insurance group for self-employed individuals (eg farmers and fishermen) as well as retirees and their dependants. The participants were followed up for 10 years following their health checkup in 1989-1991 in order to calculate the monthly medical expenditure during the followup period and to identify deceased cases. If a participant withdrew or died, the follow-up period was terminated at that time. The study obtained information on medical expenditures per participant and information on cases that withdrew from the NHI system or died, using the monthly claim history from the Shiga NHI organizations. The medical expenditure recorded in this study was restricted to the fee schedule range used in the medical insurance system in Japan, calculated as the sum of the expenditures from the insurance organization and from the beneficiary.

The arithmetic mean medical expenditure was calculated for participants grouped according to baseline characteristics measured at the health checkup. When subtracting the arithmetic mean medical expenditure of participants without the risk factor of interest from the corresponding mean of those with the factor, this residual medical expenditure crudely represented the average medical expenditure attributable to the risk factor of interest. Data on medical expenditure was logarithmically transformed to normalize the positively skewed medical expenditure distribution. Analysis of covariance was then used to compare medical expenditure strictly among characteristic groups after adjustment for potential confounding factors, including age, sex, and other cardiovascular risk factors. Log-transformed values were ultimately expressed as geometric mean medical expenditure. The present study hypothesized that a patient with a cardiovascular risk factor incurred medical expenditures not only through treatment of the factor itself but also through very expensive procedures required for associated severe vascular diseases. To support this hypothesis, the hazard ratio for all-cause mortality was also calculated using a Cox proportional hazards model incorporating the same covariates.

According to the obesity classifications of the World Health Organization $^{13}$ and the Japan Society for the Study of Obesity, ${ }^{14}$ the participants were categorized into one of the following 4 groups: body mass index (BMI) $<18.5 \mathrm{~kg} / \mathrm{m}^{2}$; BMI $18.5-24.9 \mathrm{~kg} / \mathrm{m}^{2}$; BMI $25.0-29.9 \mathrm{~kg} / \mathrm{m}^{2}$; and BMI $\geq 30.0 \mathrm{~kg} / \mathrm{m}^{2}$. A J-shaped relationship existed between BMI and medical expenditure, with the nadir of the curve occurring at a BMI of $18.5-24.9 \mathrm{~kg} / \mathrm{m}^{2}$, even after adjustment for potential confounders (Figure 1). ${ }^{9}$ In contrast, BMI showed an inversely J-shaped relationship with all-cause mortality. Underweight participants may have incurred medical expenditures and increased mortality risks as a result of a pre-existing severe disease that potentially contributed to their low weight at baseline. ${ }^{15}$

According to the 7th report of the Joint National Committee in the United States, ${ }^{16}$ the participants who were not taking antihypertensive medication and did not have a history of cardiovascular disease were categorized into one of the following 4 groups: normotension (systolic blood pressure [SBP] $<120 \mathrm{~mm} \mathrm{Hg}$ and diastolic blood pressure [DBP] $<80 \mathrm{~mm} \mathrm{Hg}$ ); pre-hypertension (SBP 120-139 $\mathrm{mm} \mathrm{Hg}$ and/or DBP $80-89 \mathrm{~mm} \mathrm{Hg}$ ); stage 1 hypertension (SBP 140$159 \mathrm{~mm} \mathrm{Hg}$ and/or DBP $90-99 \mathrm{~mm} \mathrm{Hg}$ ); and stage 2 hypertension ( $\mathrm{SBP} \geq 160 \mathrm{~mm} \mathrm{Hg}$ and/or $\mathrm{DBP} \geq 100 \mathrm{~mm} \mathrm{Hg}$ ). 


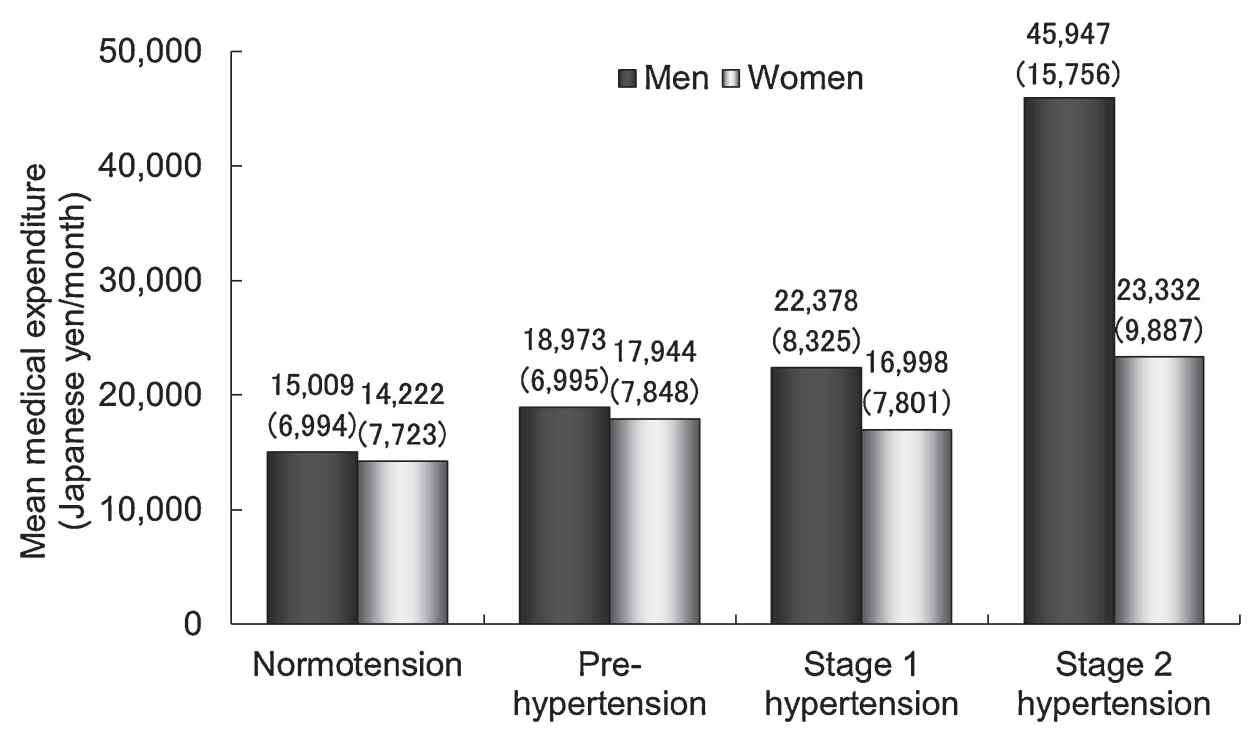

Figure 2. The crude arithmetic mean medical expenditure per month over 10 years of follow-up in male and female Japanese medical insurance beneficiaries 40-69 years of age, grouped according to their sex and hypertension status. Numbers in parentheses represent the geometric means after adjustment for age, body mass index, smoking and drinking habits, serum total cholesterol levels, and a history of diabetes (analysis of covariance, $P<0.01$ for men and $P=0.18$ for women). ${ }^{5}$

Medical expenditure tended to increase with the severity of hypertension, especially in men (Figure 2$).^{5}$ The risk of allcause mortality was also higher in stage 2 hypertensive men than in normotensive men, with a multivariate-adjusted hazard ratio of 3.19 (95\% confidence interval [CI] 1.67-6.08).

Medical expenditure was higher in diabetic participants, who were defined as having a history of diabetes as assessed by a self-reported questionnaire, than in non-diabetic participants (crude arithmetic mean 39479 vs. 19573 Japanese yen/month; multivariate-adjusted geometric mean 15788 vs. 8325 Japanese yen/month; $P<0.01) .{ }^{11}$ The risk of all-cause mortality tended to be higher in diabetic than in nondiabetic participants, with a multivariate-adjusted hazard ratio of 1.45 (95\% CI $0.86-2.47$ ).

Medical expenditure was higher in participants who had proteinuria, identified using a spot urine dipstick test, than in those who did not have this condition (crude arithmetic mean 37494 vs. 20029 Japanese yen/month; multivariate-adjusted geometric mean 14200 vs. 8451 Japanese yen/month; $P<$ $0.01){ }^{8}$ Proteinuria tended to increase the risk of all-cause mortality, with a multivariate-adjusted hazard ratio of 1.60 (95\% CI 0.64-4.03).

Hypertension and diabetes coexist in a single individual mainly due to insulin resistance accompanied by compensatory hyperinsulinemia, ${ }^{17,18}$ which occurs more frequently in obese than in non-obese individuals. ${ }^{19,20}$ The participants were categorized into one of the following 4 groups: neither hypertension nor diabetes; hypertension alone; diabetes alone; or both hypertension and diabetes. Hypertension was defined as SBP $\geq 140 \mathrm{~mm} \mathrm{Hg}$, DBP $\geq 90 \mathrm{~mm} \mathrm{Hg}$, and/or taking antihypertensive medication, while diabetes was defined as described above. Participants with both hypertension and diabetes had the highest medical expenditure among the 4 groups (Figure 3). ${ }^{7}$ These participants also had the highest risk of all-cause mortality, with a multivariate-adjusted hazard ratio of 2.21 (95\% CI 1.11-4.42), relative to those with neither hypertension nor diabetes.

Medical expenditure broadly increased with the number of concomitant cardiovascular risk factors, including hypertension, diabetes, and hypercholesterolemia, which was defined as a serum total cholesterol $\geq 220 \mathrm{mg} / \mathrm{dL} .{ }^{10}$ Although this pattern was similar in participants both with and without obesity, defined as a BMI $\geq 25.0 \mathrm{~kg} / \mathrm{m}^{2}$, obesity resulted in additional medical expenditures related to hypertension, diabetes, and hypercholesterolemia in each group.

\section{A POPULATION PERSPECTIVE ON THE RELATIONSHIP BETWEEN CARDIOVASCULAR RISK FACTORS AND MEDICAL EXPENDITURE}

The Shiga NHI cohort study estimated medical expenditures attributable to cardiovascular risk factors from a population perspective using the population attributable fraction concept as follows:

([arithmetic mean of medical expenditure in participants who had a risk factor of interest - arithmetic mean of medical expenditures in participants who did not have the factor] $\times$ number of participants who had the factor) /medical expenditure incurred in the entire population

This represents the possible reduction in medical expenditure, given that the risk factor of interest is eliminated from the entire population completely. 


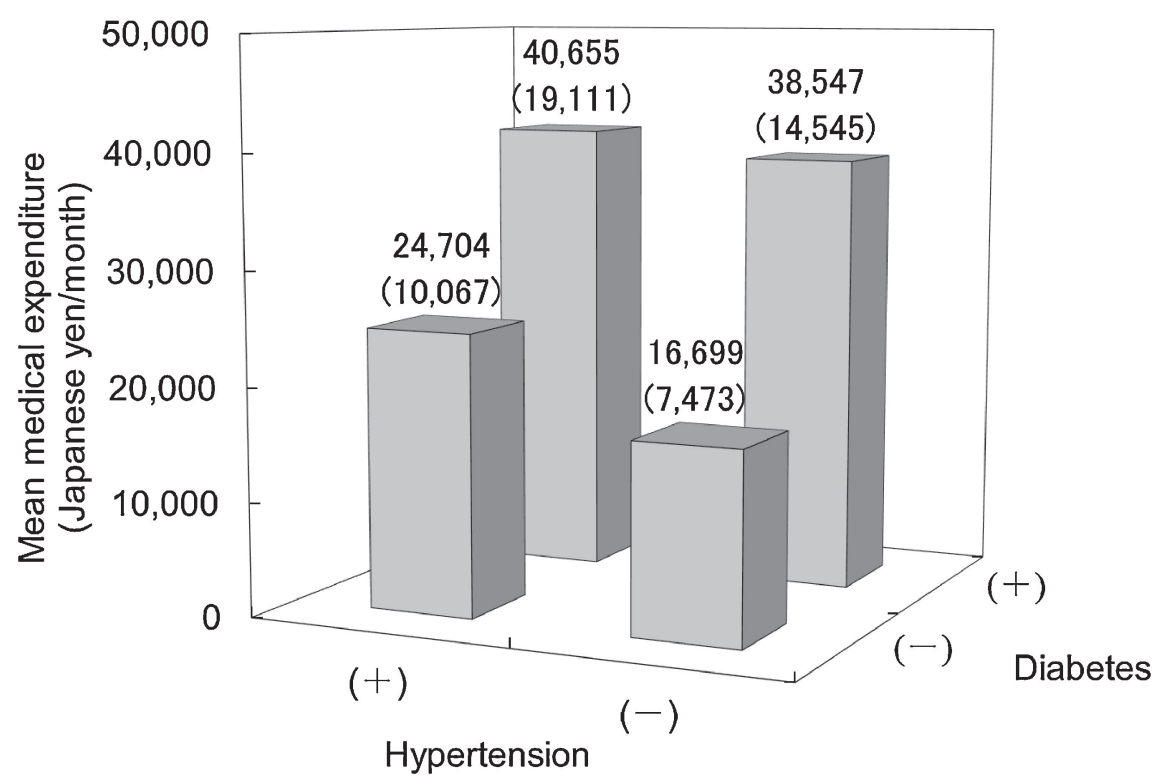

Figure 3. The crude arithmetic mean medical expenditure per month over 10 years of follow-up in Japanese medical insurance beneficiaries 40-69 years of age, grouped according to their hypertension and diabetes statuses. Numbers in parentheses represent geometric mean after adjustment for age, sex, body mass index, smoking drinking habits, and serum total cholesterol levels (analysis of covariance, $P<0.01$ ). ${ }^{7}$

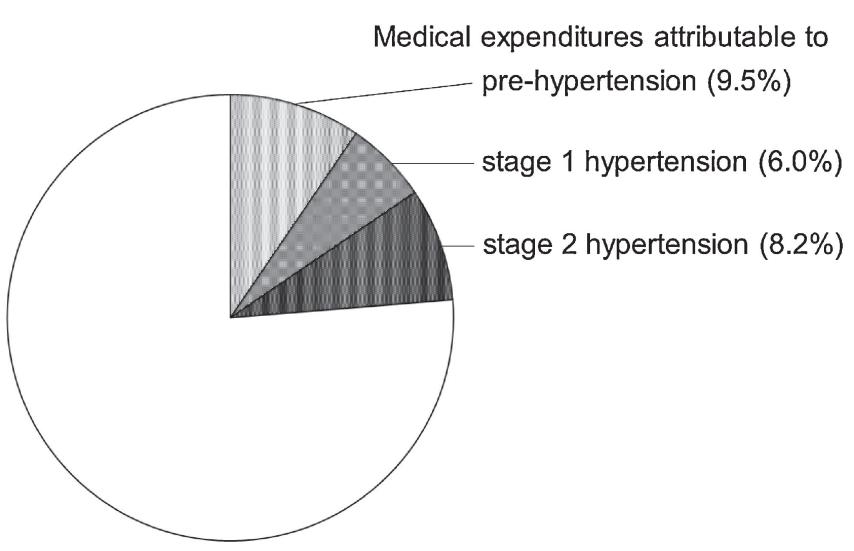

Figure 4. The percentage of medical expenditures attributable to pre-, stage 1 , and stage 2 hypertension for the entire population of Japanese medical insurance beneficiaries 40-69 years of age (19090468 Japanese yen/month/1000 persons, $100 \%) .^{5}$

The medical expenditure attributable to obesity (BMI $\geq 25 \mathrm{~kg} / \mathrm{m}^{2}$ ) accounted for $3.1 \%$ of that incurred in the entire population. $^{9}$

The medical expenditure attributable to hypertension (including pre-hypertension) accounted for $23.7 \%$ of that incurred in the entire population (Figure 4). ${ }^{5}$ The medical expenditure percentages according to the hypertension grade were $9.5 \%$ for the pre-hypertension group, $6.0 \%$ for the stage 1 hypertension group, and $8.2 \%$ for the stage 2 hypertension group.

The medical expenditure attributable to obesity and/or metabolic disorders, including hypertension, diabetes, and hypercholesterolemia, accounted for $23.6 \%$ of that incurred in the entire population. ${ }^{10}$ The percentages were $13.1 \%$ for the presence of any 1 of the 3 metabolic disorder without obesity, $3.4 \%$ for the presence of any 2 or 3 of the 3 metabolic disorders without obesity, $2.4 \%$ for obesity alone, $1.8 \%$ for the presence of any 1 of the 3 metabolic disorders plus obesity, and $2.9 \%$ for the presence of any 2 or 3 of the 3 metabolic disorders plus obesity.

\section{EVIDENCE DERIVED FROM RELEVANT LARGE COHORT STUDIES}

The second Shiga NHI cohort study included NHI beneficiaries from all 26 local municipalities of Shiga prefecture and collected data from their health checkup in 2000 and medical expenditures for up to 6 years between the fiscal years of 2000 and 2005. ${ }^{21}$

The mean medical expenditure per year during the followup period was calculated for participants 40 years of age or older $(n=33213)$ who were grouped by age and sex according to the number of cardiovascular risk factors each participant had at baseline: none of 4 cardiovascular risk factors (hypertension, hypercholesterolemia, high blood glucose, and current smoking); any 1 of the 4 factors; any 2 of the 4 factors; and any 3 or 4 of the 4 factors. These 4 cardiovascular risk factors were defined as follows: hypertension, defined as SBP $\geq 140 \mathrm{~mm} \mathrm{Hg}$ and/or DBP $\geq 90 \mathrm{~mm} \mathrm{Hg}$; hypercholesterolemia, defined as serum total cholesterol $\geq 240 \mathrm{mg} / \mathrm{dL}$; high blood glucose, defined as casual blood glucose $\geq 200 \mathrm{mg} / \mathrm{dL}$; and smoking, defined as currently smoking. The study estimated the adjusted mean medical expenditure on a real scale for the 4 age- and sex-specific groups using a gamma regression model, which is a type of 


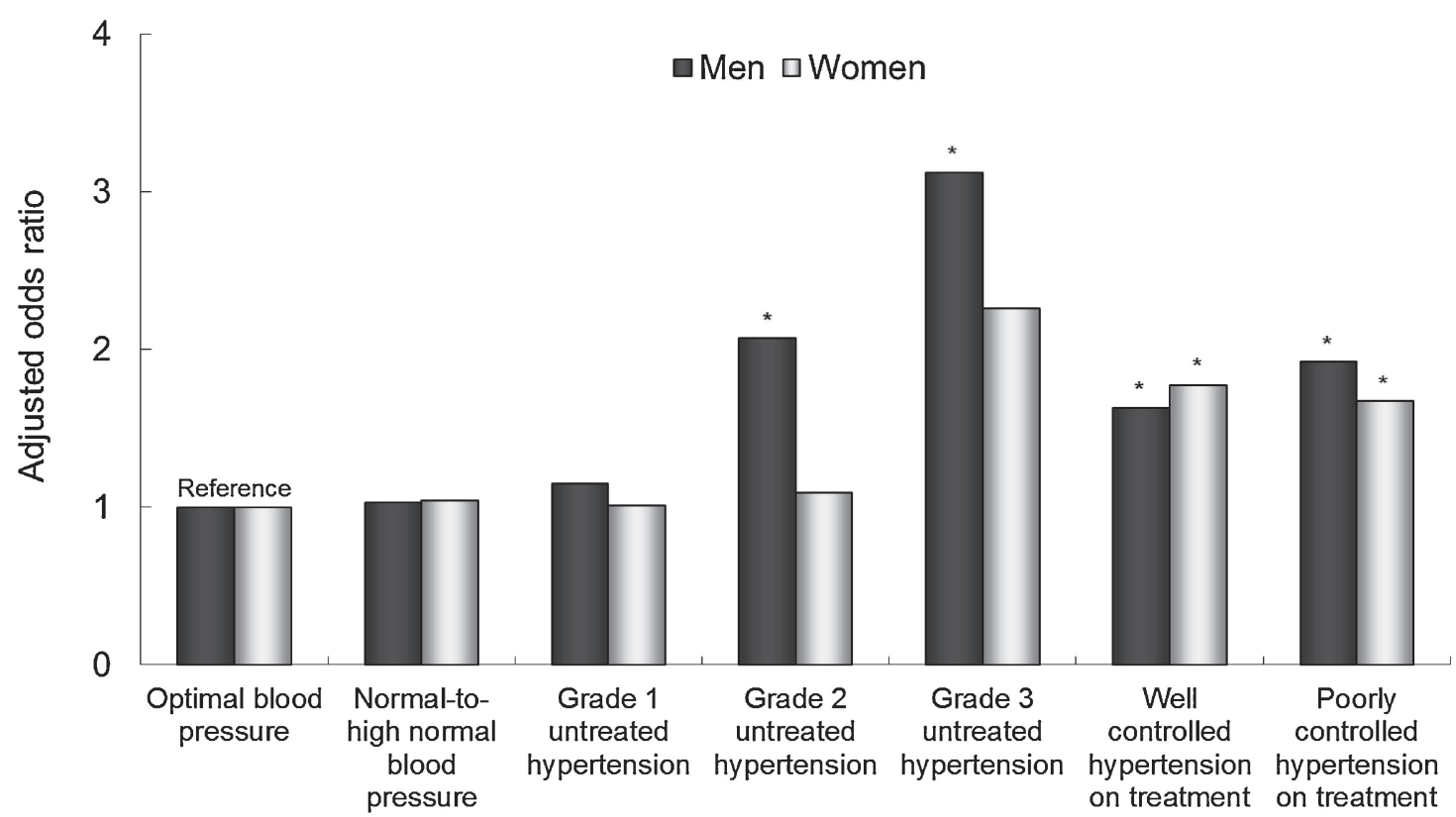

Figure 5. The adjusted odds ratios for being in the top $1 \%$ medical expenditure group over 1 year of follow-up in male and female Japanese medical insurance beneficiaries 40-54 years of age, grouped according to their hypertension status. Adjustments were made for age, body mass index, smoking habits, serum low-density lipoprotein cholesterol levels, log-transformed fasting plasma glucose levels, and medications for hypercholesterolemia and diabetes (a logistic regression model, $* P<0.05$ vs. optimal blood pressure) ${ }^{23}$

generalised linear model. ${ }^{22}$ This model has recently been considered the best modelling approach to handle medical expenditure data that allows for potential confounders. The mean medical expenditure increased with the number of concomitant cardiovascular risk factors, irrespective of age or sex. ${ }^{21}$ The mean medical expenditure was 6-to-7-fold higher for participants at age 80 who had any 3 or 4 of the 4 risk factors (men: 603351 Japanese yen/year; women: 765673 Japanese yen/year) compared with those at age 50 who had none of the 4 risk factors (men: 110708 Japanese yen/year; women: 107109 Japanese yen/year).

A tremendously large cohort study collected similar data throughout Japan and included beneficiaries of both NHI (12 local organizations) and the Employee's Health Insurance scheme (9 local organizations). ${ }^{23}$ Currently, approximately two-thirds of all Japanese people younger than 75 years of age are enrolled in Employee's Health Insurance schemes available to employees and their dependants, while the remaining are enrolled in NHI. ${ }^{1}$ The study collected data on medical expenditure for the year of 2009 after their health checkup in 2008.

Moturu et al suggested that a very small portion of patients accounted for a substantial percentage of the medical expenditure in the entire population. ${ }^{24}$ In fact, male and female study participants who ranked in the top $1 \%$ for medical expenditures incurred costs of at least 1807710 and 1437650 Japanese yen/year, respectively (data edited for currency translation), while the respective medical expenditure sums in these top $1 \%$ male and female groups accounted for $25.6 \%$ and $21.2 \%$ of medical expenditures incurred in the entire male and female populations 40-69 years of age $(n=314622){ }^{23}$ The corresponding male and female groups showed median cumulative hospitalization periods of 38 and 32 days, respectively. The study compared the risk of being in the top $1 \%$ medical expenditure group in the year following the baseline survey among age- and sexspecific participants grouped according to blood pressure and antihypertensive medication status at baseline. Participants who were not taking antihypertensive medication were categorized into 1 of the following 5 groups defined according to the 2007 criteria of the European Society of Hypertension and the European Society of Cardiology ${ }^{25}$ : optimal blood pressure (SBP $<120 \mathrm{~mm} \mathrm{Hg}$ and DBP $<80 \mathrm{~mm} \mathrm{Hg}$ ); normal-to-high-normal blood pressure (SBP $120-139 \mathrm{~mm} \mathrm{Hg}$ and/or DBP $\quad 80-89 \mathrm{~mm} \mathrm{Hg}$ ); grade 1 hypertension (SBP $140-159 \mathrm{~mm} \mathrm{Hg}$ and/or DBP 90-99 $\mathrm{mm} \mathrm{Hg}$ ); grade 2 hypertension (SBP $160-179 \mathrm{~mm} \mathrm{Hg}$ and/or DBP 100-109 $\mathrm{mm} \mathrm{Hg}$ ); and grade 3 hypertension (SBP $\geq 180 \mathrm{~mm} \mathrm{Hg}$ and/or DBP $\geq 110 \mathrm{~mm} \mathrm{Hg}$ ). The remaining participants, who were taking antihypertensive medication, were classified into one of the following 2 groups: wellcontrolled hypertension on treatment (SBP $<140 \mathrm{~mm} \mathrm{Hg}$ and DBP $<90 \mathrm{~mm} \mathrm{Hg}$ on medication); and poorly-controlled hypertension on treatment ( $\mathrm{SBP} \geq 140 \mathrm{~mm} \mathrm{Hg}$ and/or DBP $\geq 90 \mathrm{~mm} \mathrm{Hg}$ on medication). The risk of incurring such extremely high medical expenditures increased with more severe, untreated hypertension in men aged $40-54$ or 55-69 years and in women aged 40-54 years (Figure 5; results presented only for men and women aged $40-54$ years). In men and women aged 40-54 years, the grade 2-to-3 untreated 
hypertension group had an even greater risk of incurring higher medical expenditures than the well-controlled hypertension on treatment group.

\section{CONCLUSIONS AND FUTURE DIRECTIONS}

Patients with cardiovascular risk factors may incur medical expenditures though both treatments of the risk factors themselves and procedures for associated diseases that usually require hospitalization and sometimes result in death. Untreated risk factors may cause medical expenditure surges, mainly due to long-term hospitalization, more often than risk factors preventatively treated by medication. On an individual patient level, medical expenditures increase with the number of concomitant risk factors. For single risk factors, personal medical expenditure may increase with the severity of that factor. However, on a population level, the medical economic burden attributable to cardiovascular risk factors results largely from a single, particularly prevalent risk factor, especially from mildly-to-moderately abnormal levels of the factor. This is explained by Rose's theory that 'a large number of people exposed to a small risk may generate many more cases than a small number exposed to high risk ${ }^{26}$ Therefore, cardiovascular risk factors require management on the basis of 2 strategies for reducing both the ill health and medical economic burdens resulting from cardiovascular disease. One is a cost-effective strategy of treating high-risk individuals based on the assumption that the treatment of cardiovascular risk factors themselves is essential for preventing cardiovascular disease in individuals with risk factors. The second is a population strategy which aims to shift the entire population to more desirable physical profiles from current ones. Risk factors that are directly linked to undesirable lifestyle habits, such as smoking and excessive alcohol intake, might be important targets for this purpose, as lifestyle modifications may lead directly to cost-effective elimination of the corresponding risk factors and subsequently to reduction of the overall medical economic burden. ${ }^{12,27}$

To reduce both the ill health and medical economic burdens resulting from cardiovascular disease, the Japanese national government introduced a nationwide public health strategy in 2008. ${ }^{1,28,29}$ Individuals with cardiovascular risk factors, including mildly elevated blood pressure and mildly deregulated lipid and glucose metabolism, especially those with obesity, are considered candidates for incurring medical expenditure; consequently, various modes of intervention are used in these individuals, depending on the number and severity of risk factors. Therefore, medical staff and health care planners need to acknowledge the importance of this issue. Larger cohort studies are expected to provide more reliable and useful evidence on this subject. It is also important to contribute new statistical analysis methods and interesting ideas to this topic in future studies.

\section{ONLINE ONLY MATERIALS}

Abstract in Japanese.

\section{ACKNOWLEDGEMENTS}

The author is grateful to Drs. Hirotsugu Ueshima (Shiga University of Medical Science), Tomonori Okamura (Keio University), Mark Woodward (The George Institute for Global Health/Johns Hopkins University), Rachel Huxley (University of Queensland), Hideaki Nakagawa (Kanazawa Medical University), and Akira Okayama (Research Institute of Strategy for Prevention), as well as to all co-investigators, staff members, and study participants. The author also thanks the Japan Epidemiological Association and the Editorial Board of the Journal of Epidemiology for commissioning this article.

Conflicts of interest: None declared.

\section{Funding}

These studies were supported by a Grant-in-Aid from the Ministry of Health, Labour and Welfare, Health and Labour Sciences Research Grants, Japan (Comprehensive Research on Cardiovascular and Life-Style Related Disease: H17kenko-007, H18-junkankitou [seishuu]-ippan-012, H20junkankitou [seishuu]-ippan-013, H22-junkankitou [seishuu]ippan-012, H23-junkankitou [seishuu]-ippan-005; Research on Cardiovascular Disease: 20K-6; Research on Policy Planning and Evaluation: H20-seisaku-ippan-014, and H23seisaku-ippan-003).

\section{REFERENCES}

1. Health and Welfare Statistics Association. 2013/2014 Kokumin Eisei no Doko (Trend for National Health and Hygiene, Japan). Tokyo: Health and Welfare Statistics Association; 2013 (in Japanese).

2. Yoshida M, Takada T, Hirata K, Mayumi T, Shikata S, Shirai K, et al. Health insurance and payment systems for severe acute pancreatitis. J Hepatobiliary Pancreat Sci. 2010;17:13-6.

3. Okamura S, Kobayashi R, Sakamaki T. Case-mix payment in Japanese medical care. Health Policy. 2005;74:282-6.

4. Kanda H, Nakamura K, Hayakawa T, Okamura T, Ueshima H. The influence of alcohol drinking on medical care expenditures among National Health Insurance beneficiaries. Nihon Arukoru Yakubutsu Igakkai Zasshi (Jpn J Alcohol \& Drug Dependence). 2005;40:171-80 (in Japanese).

5. Nakamura K, Okamura T, Kanda H, Hayakawa T, Kadowaki T, Okayama A, et al; Health Promotion Research Committee of the Shiga National Insurance Organizations. Impact of hypertension on medical economics: A 10-year follow-up study of national health insurance in Shiga, Japan. Hypertens Res. 2005;28: 859-64.

6. Nakamura K, Okamura T, Kanda H, Hayakawa T, Okayama A, Ueshima H; Health Promotion Research Committee of the Shiga 
National Health Insurance Organizations. The value of combining serum alanine aminotransferase levels and body mass index to predict mortality and medical costs: a 10-year follow-up study of National Health Insurance in Shiga, Japan. J Epidemiol. 2006;16:15-20.

7. Nakamura K, Okamura T, Kanda H, Hayakawa T, Okayama A, Ueshima H; Health Promotion Research Committee of the Shiga National Health Insurance Organizations. Medical costs of patients with hypertension and/or diabetes: A 10-year followup study of National Health Insurance in Shiga, Japan. J Hypertens. 2006;24:2305-9.

8. Nakamura K, Okamura T, Kanda H, Hayakawa T, Okayama A, Ueshima H; Health Promotion Research Committee of the Shiga National Health Insurance Organizations. Medical costs of individuals with proteinuria: A 10-year follow-up study of National Health Insurance in Shiga, Japan. Public Health. 2007;121:174-6.

9. Nakamura K, Okamura T, Kanda H, Hayakawa T, Okayama A, Ueshima H; Health Promotion Research Committee of the Shiga National Health Insurance Organizations. Medical costs of obese Japanese: a 10-year follow-up study of National Health Insurance in Shiga, Japan. Eur J Public Health. 2007;17:424-9.

10. Okamura T, Nakamura K, Kanda H, Hayakawa T, Hozawa A, Murakami Y, et al; Health Promotion Research Committee, Shiga National Health Insurance Organizations. Effect of combined cardiovascular risk factors on individual and population medical expenditures: a 10-year cohort study of national health insurance in a Japanese population. Circ J. 2007;71:807-13.

11. Nakamura K, Okamura T, Kanda H, Hayakawa T, Murakami Y, Okayama A, et al; Health Promotion Research Committee Of The Shiga National Health Insurance Organizations. Medical expenditure for diabetic patients: a 10-year follow-up study of National Health Insurance in Shiga, Japan. Public Health. 2008;122:1226-8.

12. Nakamura K, Okamura T, Hayakawa T, Kanda H, Okayama A, Ueshima H; Health Promotion Research Committee of the Shiga National Health Insurance Organizations. Medical expenditures of men with hypertension and/or a smoking habit: a 10-year follow-up study of National Health Insurance in Shiga, Japan. Hypertens Res. 2010;33:802-7.

13. World Health Organization. Obesity. Preventing and Managing the Global Endemic. WHO Technical Report Series no 894. Geneva: WHO; 2000.

14. The Examination Committee of Criteria for 'Obesity Disease' in Japan, Japan Society for the study of Obesity. New criteria for 'obesity disease' in Japan. Circ J. 2002;66:987-92.

15. Wannamethee SG, Shaper AG, Walker M. Weight change, body weight and mortality: the impact of smoking and ill health. Int J Epidemiol. 2001;30:777-86.

16. Chobanian AV, Bakris GL, Black HR, Cushman WC, Green LA, Izzo JL Jr, et al; National Heart, Lung, and Blood Institute Joint National Committee on Prevention, Detection, Evaluation, and Treatment of High Blood Pressure; National High Blood Pressure Education Program Coordinating Committee. The
Seventh Report of the Joint National Committee on Prevention, Detection, Evaluation, and Treatment of High Blood Pressure: the JNC 7 report. JAMA. 2003;289:2560-72 (errata: JAMA. 2003;290:197).

17. Zavaroni I, Bonora E, Pagliara M, Dall'Aglio E, Luchetti L, Buonanno $G$, et al. Risk factors for coronary artery disease in healthy persons with hyperinsulinemia and normal glucose tolerance. N Engl J Med. 1989;320:702-6.

18. Haffner SM, Valdez RA, Hazuda HP, Mitchell BD, Morales PA, Stern MP. Prospective analysis of the insulin-resistance syndrome (syndrome X). Diabetes. 1992;41:715-22.

19. Stern JS, Batchelor BR, Hollander N, Cohn CK, Hirsch J. Adipose-cell size and immunoreactive insulin levels in obese and normal-weight adults. Lancet. 1972;2:948-51.

20. Ludvik B, Nolan JJ, Baloga J, Sacks D, Olefsky J. Effect of obesity on insulin resistance in normal subjects and patients with NIDDM. Diabetes. 1995;44:1121-5.

21. Murakami Y, Okamura T, Nakamura K, Miura K, Ueshima H. The clustering of cardiovascular disease risk factors and their impacts on annual medical expenditure in Japan: communitybased cost analysis using Gamma regression models. BMJ Open. 2013;3:e002234.

22. Fitzmaurice GM, Laird NM, Ware JH. Applied longitudinal analysis. 2nd ed. Hoboken: John Wiley \& Sons; 2011.

23. Nakamura K, Miura K, Nakagawa H, Okamura T, Okuda N, Nishimura K, et al. Treated and untreated hypertension, hospitalization, and medical expenditure: an epidemiological study in 314622 beneficiaries of the medical insurance system in Japan. J Hypertens. 2013;31:1032-42.

24. Moturu ST, Johnson WG, Liu H. Predictive risk modelling for forecasting high-cost patients: a real-world application using Medicaid data. Int J Biomed Eng Technol. 2010;3:114-32.

25. Mancia G, De Backer G, Dominiczak A, Cifkova R, Fagard R, Germano G, et al; Management of Arterial Hypertension of the European Society of Hypertension; European Society of Cardiology. 2007 Guidelines for the Management of Arterial Hypertension: The Task Force for the Management of Arterial Hypertension of the European Society of Hypertension (ESH) and of the European Society of Cardiology (ESC). J Hypertens. 2007;25:1105-87 (errata: J Hypertens. 2007;25:1749).

26. Rose G. Sick individuals and sick populations. Int J Epidemiol. 1985;14:32-8.

27. Nakamura K, Sakurai M, Miura K, Morikawa Y, Nagasawa SY, Ishizaki $\mathrm{M}$, et al. Nicotine dependence and cost-effectiveness of individualized support for smoking cessation: evidence from practice at a worksite in Japan. PLoS One. 2013;8:e55836.

28. Ministry of Health, Labour and Welfare of Japan. The basic guideline for health checkups and healthcare advice with a particular focus on the metabolic syndrome (final edition). Tokyo: Ministry of Health, Labour and Welfare of Japan; 2007 (in Japanese).

29. Kohro T, Furui Y, Mitsutake N, Fujii R, Morita H, Oku S, et al. The Japanese national health screening and intervention program aimed at preventing worsening of the metabolic syndrome. Int Heart J. 2008;49:193-203. 